\title{
Molecular Analysis of a Plum pox virus W Isolate in Plum Germplasm Hand Carried into the USA from the Ukraine Shows a Close Relationship to a Latvian Isolate
}

Vessela Mavrodieva, United States Department of Agriculture (USDA), Animal and Plant Health Inspection Services (APHIS), Plant Protection and Quarantine (PPQ), Center for Plant Health Science and Technology (CPHST) Beltsville Laboratory, Bldg. 580, BARCEast, Powder Mill Rd., Beltsville, MD 20705, USA; Delano James, Sidney Laboratory, Canadian Food Inspection Agency (CFIA), 8801 East Saanich Road, Sidney, BC, V8L 1H3, Canada; Karen Williams and Sarika Negi, USDA APHIS PPQ CPHST Beltsville Laboratory, Bldg. 580, BARC-East, Powder Mill Rd., Beltsville, MD 20705, USA; Aniko Varga, Sidney Laboratory, CFIA, 8801 East Saanich Road, Sidney, BC, V8L 1H3, Canada; Ray Mock, USDA, Agricultural Research Service, National Germplasm Resources Laboratory, 10300 Baltimore Ave., Beltsville, MD, USA; and Laurene Levy, USDA APHIS PPQ CPHST Beltsville Laboratory, Bldg. 580, BARC-East, Powder Mill Rd., Beltsville, MD 20705, USA

\begin{abstract}
Mavrodieva, V., James, D., Williams, K., Negi, S., Varga, A., Mock, R., and Levy, L. 2013. Molecular analysis of a Plum pox virus W isolate in plum germplasm hand carried into the USA from the Ukraine shows a close relationship to a Latvian isolate. Plant Dis. 97:44-52.

Four of 19 Prunus germplasm accessions hand carried from the Ukraine into the United States without authorization were found to be infected with Plum pox virus (PPV). Of the three isolates characterized, isolates UKR 44189 and UKR 44191 were confirmed to be isolates of PPV strain W, and UKR 44188 was confirmed to be an isolate of PPV strain D. UKR 44189 and UKR 44191 are very closely related to the PPV strain W isolate LV-145bt (HQ670748) from Latvia.

Nucleotide and amino acid sequence identities between these three isolates were greater than $99 \%$. This indicates that the isolates are very closely related and likely originated from a common source. The high genetic diversity among PPV-W strain isolates allowed the identification of potential recombination events between PPV isolates. It appears also that GF 305 peach and Prunus tomentosa are not hosts for the PPV isolate UKR 44189.
\end{abstract}

Plum pox virus (PPV) is the only member of the genus Potyvirus that infects Prunus. Since it was first described in Bulgaria (2), PPV has spread rapidly, and it is currently reported in Europe (3), Northern Africa (42), North $(17,37)$ and South America $(1,8)$, and regions of Asia $(22,36)$. PPV is a positive sense single-stranded RNA virus, naturally transmitted by several species of aphids in a nonpersistent manner. Long distance spread is mediated through human activity via distribution of infected plant material. The genetic and geographical diversity of PPV has been studied extensively and is monitored by researchers and regulatory agencies worldwide. There are seven strains of PPV currently recognized. PPV-D is the most widely distributed geographically (Europe, North and South America, and Asia) and infects most Prunus species (3). PPV-M causes more severe symptoms but so far has only been reported in Europe (3). PPV-El Amar is limited in its geographical distribution, while PPV-C has a limited natural host range (3). Three more strains have been described recently. Many PPV-M isolates have been reassigned as PPV-Rec $(10,11)$ isolates, and an unusual recombinant isolate was reported in Turkey designated as PPV-T (33). PPV-W (Winona) strain was first described in Canada on a single dooryard plum tree in $2003(12,13,15)$. Since its recent discovery, several additional PPV-W isolates have been reported, all originating from the former Soviet Republics $(9,25,34)$.

Corresponding author: Vessela Mavrodieva,

E-mail: vessela.a.mavrodieva@ aphis.usda.gov

* The $\boldsymbol{e}$-Xtra logo stands for "electronic extra" and indicates that Figure 7 appears in color in the online edition.

Accession numbers: JN596110, JN637991.

Accepted for publication 11 July 2012.

http://dx.doi.org/10.1094/PDIS-01-12-0104-RE

This article is in the public domain and not copyrightable. It may be freely reprinted with customary crediting of the source. The American Phytopathological Society, 2013.
PPV is under quarantine regulations in many countries due to its significant detrimental impact on the Prunus industry. Globalization of trade and travel has contributed to the spread of exotic plant pathogens, including PPV, to new geographical areas where the introduction of new species or strains can cause severe damage due to the presence of susceptible and/or symptomless cultivars. These pathogens may remain undetected for several years due to infection latency. PPV-D was first reported in North America in the state of Pennsylvania in 1999 (17) and in the Ontario Province of Canada in 2000 (37). In 2006, PPV-D was found in the state of New York (35) and on a single tree in Michigan (40). To date, three PPV strains have been described in Canada, namely PPV-D, -Rec, and -W $(14,38)$. All isolates detected in the United States belong to PPV-D group. After 10 years of extensive surveys and quarantine measures, Pennsylvania declared PPV eradicated in 2009. PPV was also eradicated in Michigan in 2009, and the number of PPV detections in New York has declined steadily in recent years with only one positive find in 2011. With eradication of PPV in the United States near completion, the reintroduction of any strain of PPV into the country is of great concern to the Prunus industry and the U.S. regulatory agencies. Several mechanisms are in place to guard against introduction of PPV through importation of commercial planting materials. Foreign plant material is only allowed from APHIS-certified oversees nurseries, or it is subjected to a 2-year indexing program in quarantine facilities before being released as virus- and disease-free.

Despite these safeguards, unauthorized movement of plant material is difficult to control. Prunus germplasm originating from the Ukraine was hand carried to the United States in 2004 without any official documentation. The U.S researcher who received the germplasm immediately turned the material over to regulatory officials. When subjected to virus indexing in the USDA-ARS quarantine facility in Beltsville, MD, four out of the 19 accessions were found to be infected with PPV. Of these four accessions, two were infected with PPV-W, a strain that is not known to exist in the United States (25).

In this study, we report on partial characterization of intercepted PPV isolates UKR 44186, 44188, and 44191, and the complete 
characterization of PPV-W isolate UKR 44189. Comparison of the nucleic acid (na) and amino acid (aa) sequences of UKR 44189 with other PPV-W isolates revealed a very close genetic relationship with the PPV-W isolates found in Latvia (9), and highlights the unusually high genetic variability of the PPV-W strain. Additional information available suggests a common origin of the PPV$\mathrm{W}$ isolates.

\section{Materials and Methods}

Virus source. Nineteen Prunus germplasm accessions from the Ukraine were subjected to virus indexing at the USDA-ARS Plant Germplasm Quarantine Office in Beltsville, MD. Accession 44186 was from Prunus cerasifera cv. Slivovidnaya; accession 44188 from $P$. cerasifera cv. Donchanka Rannaya; accession 44189 from $P$. spinosa (black thorn) cv. Tern Donetskiy Krupniy; and accession 44191 from Prunus sp. cv. Tatiyana. PPV W3174 isolate from Canada and PPV sour cherry isolate from Agdia Inc. (Elkhart, IN) were used as controls in addition to PPV-El Amar, PPV-D, and PPV-M isolates from our PPV collection.

UKR 44188 and UKR 44189 infected plant material was further regrafted on GF 305 peach and $P$. tomentosa indicator (rootstock) hosts. Both isolates were also mechanically transmitted to Nicotiana benthamiana by sap inoculation.

Strain-specific triple antibody sandwich-enzyme-linked immunosorbent assay (TAS-ELISA). The following strainspecific monoclonal antibodies (MAbs) were used for serological differentiation of UKR 44189 isolate: PPV-M/Rec specific AL and PPV-D specific 4DG5 from M. Cambra (IVIA, Valencia, Spain), PPV-C and PPV-El Amar specific MAbs from Agritest S.r.I. (Valenzano, Italy), and PPV W3174-derived MAbs 10G7, 2C3, 6B6, 4C11, and 4A11 (7). Plates were coated with the polyclonal capture antibody from a PPV double antibody sandwich (DAS)ELISA kit (SRA 31505, Agdia). After incubation for $4 \mathrm{~h}$ at room temperature (RT), $3 \%$ nonfat dry milk in phosphate buffered saline (PBS) was added and incubated for at least $2 \mathrm{~h}$ at RT. Leaf samples were ground in GEB4 buffer at 1/10 (wt/vol) tissue to buffer ratio. Samples were loaded onto the Ab-coated plates and incubated overnight at $4^{\circ} \mathrm{C}$. The MAbs, used as secondary antibodies, were diluted in PBS supplemented with $0.5 \%$ bovine serum albumin (BSA) and added to the washed plates. Goat anti-mouse IgG-Alkaline Phosphatase (AP) conjugate (Sigma-Aldrich, St. Louis, MO) was applied at 1/30,000 dilution. Incubations of sap, strain-specific MAbs, and the conjugate were conducted overnight at $4{ }^{\circ} \mathrm{C}$ and the plates washed with PBS with 2\% Tween 20 (PBST) after each step. After incubation with $p$-nitrophenyl phosphate (PNP) substrate, absorption was recorded at $405 \mathrm{~nm}$. Samples with O.D. values at least 2.5 times the healthy control were considered positive.

Western blot. UKR 44189 infected leaf material was prepared in Laemmli Sample Buffer (Bio-Rad, Hercules, CA). Proteins were separated using TRIS-SDS PAGE on a 4 to $15 \%$ gradient "Ready Gel" from Bio-Rad for approximately $2 \mathrm{~h}$ at $100 \mathrm{~V}$, then transferred onto nitrocellulose membrane $(0.45 \mu \mathrm{m}$, Schleicher \& Schuell). Precision Plus Protein Standards (Bio-Rad) were used to determine protein size. Immun-Blot Goat Anti-Mouse $\operatorname{IgG}(\mathrm{H}+\mathrm{L})$-AP Assay kit (Bio-Rad) was used according to the manufacturer's manual. The PPV universal 5B MAb from REAL (Durviz S.L.U., Valencia, Spain) was diluted 1/1,000 and PPV-W3174 specific monoclonal antibodies 10G7 and 2C3 were used in 1/500 dilution. PPV-D infected GF305 leaves and W3174 infected lyophilized tissue were used as controls.

Immunocapture-reverse transcription-polymerase chain reaction (IC-RT-PCR). Immunocapture of PPV was performed according to Wetzel et al. (41) with some modification. The Bioreba polyclonal anti-PPV IgG (Reinach, Switzerland) was diluted $1 / 200$ in carbonate buffer, $\mathrm{pH} 9.2$, and used to coat $1.5-\mathrm{ml}$ disposable tubes. After incubation at $37^{\circ} \mathrm{C}$ for $2 \mathrm{~h}$, plant sap $(1 / 10$ tissue to buffer ratio) was added to the tubes and incubated overnight at $4^{\circ} \mathrm{C}$. Tubes were washed with PBST before and after incubation of plant sap. The virus was released in $\mathrm{dH}_{2} \mathrm{O}$ by incubating the tubes at $65^{\circ} \mathrm{C}$ for $5 \mathrm{~min}$. RT-PCR was conducted using the PPV universal primers $\mathrm{P} 1-\mathrm{P} 2$ targeting the $\mathrm{C}$-terminal region of the coat protein (CP) coding region to produce a 243 -bp amplicon (43), or $3^{\prime}$ NTR primers (18) targeting the $3^{\prime} \mathrm{NCR}$ of the PPV genome using established protocols.

Strain determination. PPV strain determination of the Ukrainian isolates was accomplished using IC-RT-PCR with PPV-D and PPV-M strain-specific primers (4). In addition, the P1-P2 PCR products were subjected to $A l u \mathrm{I}$ and $R s a \mathrm{I}$ digestion at $37^{\circ} \mathrm{C}$ overnight. RT-PCR with PPV-W specific primers (3174SP-F3/R1) was performed according to the published protocol (12) to confirm strain determination of UKR 44189.

Total RNA extraction and cDNA synthesis. Total plant RNA was extracted from PPV infected or healthy Prunus leaves using the RNeasy Plant Mini kit (Qiagen Inc., Valencia, CA) with some modifications according to MacKenzie et al. (21). The SuperScript III First Strand Synthesis SuperMix from Invitrogen (Carlsbad, CA) was used to generate cDNA with PPV specific primers and/or random hexamers according to the manufacturer's instructions.

Primers. To obtain the full-length sequence of PPV isolate UKR 44189, virus-specific oligonucleotide primers were designed using the published PPV W3174 sequence (AY912055). Additionally, primers were designed based on the already existing UKR 44189 sequence (i) when some of the cloning primers did not produce any PCR products, (ii) when needed for sequencing of the long PCR products, or (iii) to verify overlapping regions. The primers published by Nemchinov et al. (26) were used to amplify the $3^{\prime}$ end 1.4 nt portion of the genome.

Full-genome sequencing and assembly. Full genome sequence of UKR 44189 was obtained using two approaches. The first approach employed RT-PCR using Titan One Tube RT-PCR System (Roche Applied Science, Indianapolis, IN) to generate PCR fragments that were cloned into pCR®2.1 TOPO vector (Invitrogen). At least three clones per fragment were sequenced in both directions. In a second approach, primers were designed to generate long PCR fragments after amplification of cDNA with TaKaRa SpeedSTAR ${ }^{\mathrm{TM}}$ HS DNA Polymerase (Clontech, Mountain View, CA). These PCR fragments were subjected to direct sequencing in both directions. To obtain the $5^{\prime}$ end of the UKR 44189 genome, the 5' RACE System from Invitrogen was used. Sequencing was conducted at the DNA Sequencing Facility of the University of Maryland (College Park, MD). The full-length genome was assembled using the DNASTAR Lasergene MegAlign version 9 (Madison, WI), where each fragment was represented by at least one sequence in each direction except for the $3^{\prime}$ end of the genome that represents the primer sequence ( $24 \mathrm{nt}$ ).

Sequence analysis. Multiple alignments and phylogenetic analyses (bootstrap values of 1,000 replicates) were carried out using the neighbor-joining method described by Saitou and Nei (31), in Clustal X version 1.83. Phylogenetic trees were constructed using NJ-PLOT described by Perriere and Gouy (29). The SimPlot program version 3.5.2 (19) was used to screen sequences for signals of recombination events. The RDP3 program (23) was used in attempts to verify any recombination signals observed. Protein molecular weights were determined using Compute $\mathrm{pI} / \mathrm{Mw}$, SwissProt/TrEMBL (44).

\section{Results}

Virus detection. GF 305 peach rootstock grafted with accession 44188 , received from the Donetsk Branch of the Institute of Horticulture in Ukraine, showed typical PPV symptoms including leaf vein clearing and crinkling. DAS-ELISA and IC-RT-PCR with the universal 3'NTR primers were used to detect PPV in four of the 19 Prunus accessions from the same source (44186, 44188, 44189, and 44191; results not shown). Isolate UKR 44188 was detected in leaves of both GF 305 rootstock and the accession (graft) tissue. Isolate UKR 44186 was detected in GF 305 budwood tissue only. Isolates UKR 44189 and UKR 44191 were not detected in GF 305 rootstock leaves; however, they were detected directly in shoots of the accession grafts. We were also able to detect the virus in bark scrapings of the original dormant imported budwood of accessions 
44188, 44189, and 44191, but not of accession 44186. Unfortunately, we were not able to detect PPV in accessions 44186 and 44191 soon after the initial findings and characterization.

Isolates UKR 44188 and UKR 44189 were bud-grafted again onto GF 305 peach and $P$. tomentosa host plants. The virus status of these seedlings was evaluated annually for several years. Using DAS-ELISA and real-time IC-RT-PCR, isolate UKR 44189 was detected only in the graft tissue (accession) maintained on the GF 305 peach rootstock (results not shown). UKR 44189 isolate induced mild PPV-like symptoms, chlorotic mottling, and leaf deformation, on a few branches of the graft tissue ( $P$. spinosa). Again, we were unable to detect UKR 44189 in tissue of GF 305 peach or $P$. tomentosa indicator plants. On the other hand, UKR 44188 was successfully transferred to GF 305 peach indicators and caused typical PPV-like symptoms. Both UKR 44188 and UKR 44189 were successfully mechanically transmitted to $N$. benthamiana indicator plants and caused severe mosaic symptoms and leaf deformation once infection was established. The virus was detected easily by ELISA or real-time RT-PCR, indicating a high virus titer in these plants (results not shown).

Strain determination. Isolate UKR 44188 produced a PCR fragment of the expected size with the PPV-D specific primers but failed amplification with PPV-M specific primers similarly to the PPV-D control included (Fig. 1B and C). Isolates UKR 44189 and UKR 44191 failed to amplify with either PPV-D or PPV-M specific primers (Fig. 1B and C), although they did produce the expected 243-bp product with the PPV universal P1-P2 primers (Fig. 1A). PPV-M and PPV-El Amar controls amplified with PPV-M primers only (Fig. 1C). Restriction fragment length polymorphism (RFLP) analysis of the P1-P2 fragment with $A l u \mathrm{I}$ and $R s a \mathrm{I}$ confirmed that
UKR 44188 belongs to PPV-D. UKR 44189 and UKR 44191 P1$\mathrm{P} 2$ fragments lacked both restriction sites resembling either PPV-C or PPV-W (results not shown).

Further sequencing and analysis of the 1.4-kb of the $3^{\prime}$ end of the genome was used for strain determination of isolates UKR 44189, UKR 44191, and UKR 44188. UKR 44188 (JN637991) was confirmed as a PPV-D isolate. Nucleic acid analysis of the fragments generated by UKR 44189 and UKR 44191 showed that they were almost identical to each other and exhibited the highest level of identity (93\%) with PPV W3174 (AY912055). Identity with other PPV strains was less than $80 \%$ (results not shown), which suggested that UKR 44189 and UKR 44191 belong to the newly described PPV-W strain.

For further confirmation, RT-PCR of UKR 44189 isolate was carried out with the PPV-W specific 3174SP-F3/R1 (12) primer pair. Weak PCR fragments of the correct size, $327 \mathrm{bp}$, were generated using total plant RNA (results not shown) and plasmid DNA that carried the PCR target region (Fig. 2), indicating that amplification was inefficient. Comparison of the primer site sequences of W3174 and UKR 44189 revealed a five-nucleotide mismatch in the F3 forward primer site (Fig. 3). One of the mismatches, a C/T substitution, was located in position -4 , with the others at positions $-6,-7,-10$, and -13 from the $3^{\prime}$ end of the primer. These nucleotide changes could explain the low amplification efficiency of UKR 44189 with the PPV-W 3174 SP-F3/R primers.

Serological characterization of UKR 44189. UKR 44189 isolate tested negative against strain-specific MAbs for PPV-D, -M, -El Amar, and -C (Table 1), thus confirming that this isolate did not belong to any of these strains. Based on already established similarities, TAS-ELISA and Western blot with W3174-specific

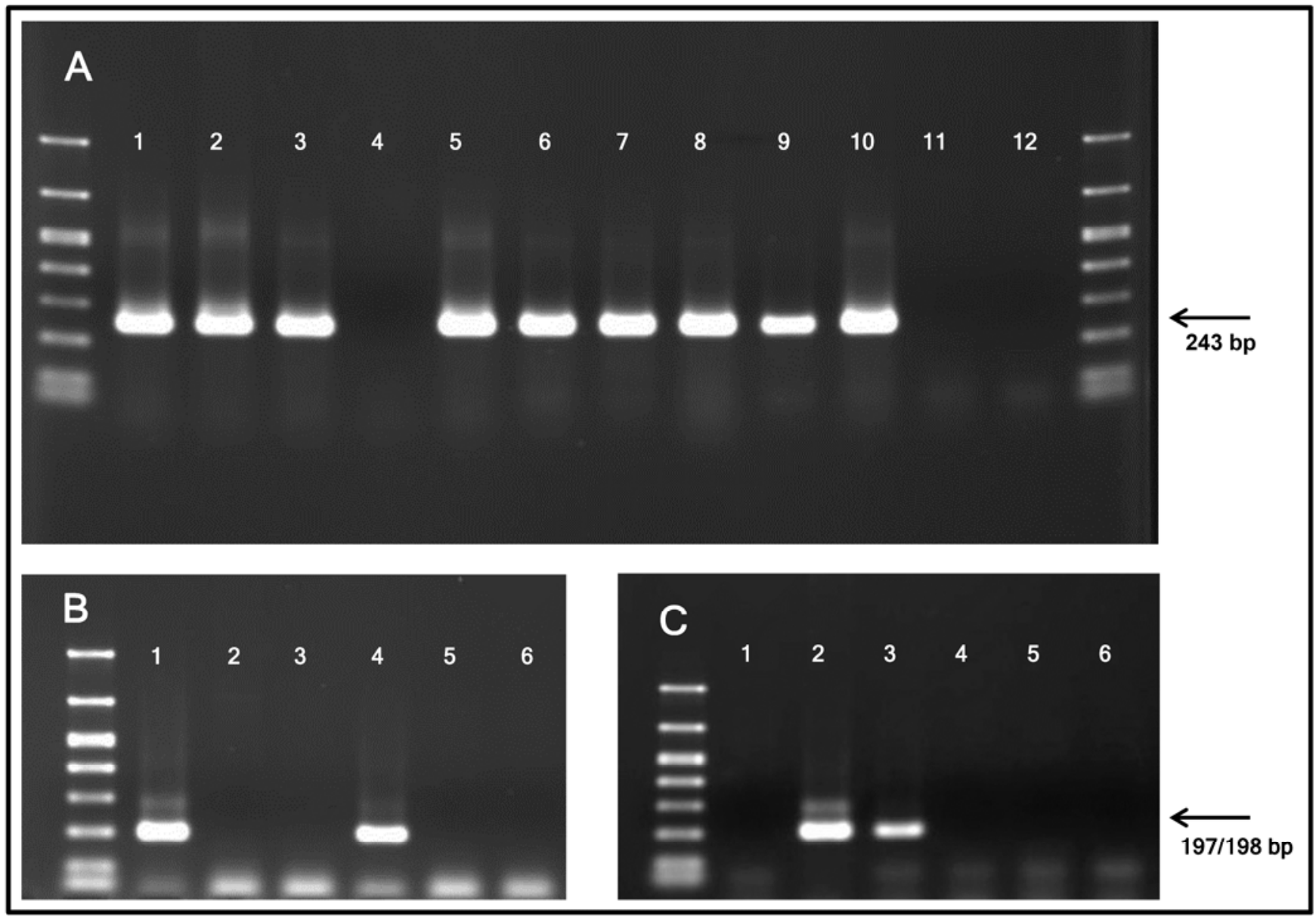

Fig. 1. Reverse transcription-polymerase chain reaction (RT-PCR) using Plum pox virus (PPV) universal P1-P2 primers (A) and PPV-D (B) and PPV-M (C) strain-specific primers. A, BioVentures BioMarker Low; 1, PPV-D; 2, PPV-M; 3, PPV-El Amar; 4, non-template control; 5 and 6, PPV 44188; 7 and 8, PPV 44189; 9 and 10, PPV 44191; 11 , healthy plant; and 12, NTC. B and C, BioVentures BioMarker Low; 1, PPV-D; 2, PPV-M; 3, PPV-El Amar; 4, PPV 44188; 5, PPV 44189; and 6, PPV 44191. 
MAbs 10G7 and 2C3 were conducted to study the serological relationship of the UKR 44189 isolate with W3174. UKR 44189 tested negative with both MAbs in either test (results not shown). Binding properties and epitope sites for some of the W3174-specific MAbs have been studied and published recently (7). MAbs 10G7 and 2C3 epitope ${ }^{2} \mathrm{DEEDD}^{6}$ is located at the very $\mathrm{N}$-terminus of the $\mathrm{CP}$ gene. In addition, the tetrapeptide ${ }^{8}$ PTIV $^{11}$, just downstream from the epitope site, was found to provide a critical context for recognition by these MAbs (7). Comparison of deduced $\mathrm{CP}$ aa sequences of UKR 44189 and W3174 (Fig. 4) revealed a substitution at position 2 where aspartic acid (D) in W3174 is replaced by asparagine (N) in UKR 44189. In the context region, proline $(\mathrm{P})$ in position 8 is replaced by serine (S), and isoleucine (I) in position 10 is missing in the UKR 44189 sequence. Therefore, lack of recognition of UKR 44189 by $10 \mathrm{G} 7$ and $2 \mathrm{C} 3$ MAbs may be due to significant sequence differences, two amino acid substitutions and one deletion, in the epitope site. Examining the UKR 44189 coat protein sequence at the epitope sites for other well characterized W3174-derived MAbs showed three amino acid substitutions in the 6F6 MAb epitope site and preservation of the epitope sequence for the 4A11 MAb (Fig. 4). The 4A11 epitope appears to be conserved not only among isolates of strain W (Fig. 4) but also across several PPV strains (7). Based on this comparison, the 6F6 MAb was not tested with UKR 44189. UKR 44189 isolate tested positive with additional W3174-derived MAbs, 6B6, 4C11, and 4A11, (Table 1) using TAS-ELISA.

Genome organization. Isolate UKR 44189 was selected for detailed genomic analysis, and the complete genome was assembled from approximately 14 RT-PCR generated fragments that were sequenced in both directions. Additional fragments were generated to confirm some of the overlapping regions. The UKR 44189 genome (JN596110) consists of 9,786 nucleotides excluding the poly-(A) tail at the $3^{\prime}$ end of the genome, and is monocistronic encoding a single open reading frame. The AUG translation initiation codon was identified at 147-149 position and the stop codon at 9567-9569 position. The resulting putative polyprotein was 3,140 aa long with estimated $M \mathrm{r}$ of $355.8 \mathrm{kDa}$, while the $\mathrm{CP}$ was 330 aa long with an estimated $\mathrm{Mr}$ of $36.4 \mathrm{kDa}$.

Sequence analysis. The complete genome of UKR 44189 showed identity of $78 \%$ with PPV-D, PPV-M, PPV-Rec, and PPV-
T, 79\% with PPV-C, and 77\% with PPV-El Amar isolates. Identity with PPV-W isolates ranged from $92 \%$ with W3174 (AY912055) to $99 \%$ with LV-145bt (HQ670748), a PPV-W isolate from Latvia (9). When polyprotein sequences were compared, the percent identity of UKR 44189 to non-PPV-W isolates increased to 88$89 \%$, suggesting silent mutations at the nucleic acid level. Interestingly, of all PPV isolates in GenBank other than PPV-W isolates, two newly described isolates from Belarus, BY101 (HQ840517) and BY181 (HQ840518), showed higher amino acid identity to UKR 44189 at $90 \%$. Within PPV-W isolates, UKR 44189 showed highest aa identity of $99.6 \%$ to LV-145bt and lowest identity of $97.4 \%$ to W3174. UKR 44189 polyprotein differed from LV-145bt by a total of 13 amino acids, with most of the substitutions, three each, located in the $\mathrm{P} 3, \mathrm{CI}$, and $\mathrm{NIb}$ protein regions. CP sequence comparison between UKR 44189 and LV145 bt exhibited 99.8 and $99.7 \%$ identity for na and aa sequences, respectively, with a single amino acid substitution (N/S) at position 257. The CP-1 N-terminus region (6) of the UKR 44189 and LV$145 \mathrm{bt}$ isolates is $100 \%$ identical for both the nucleotide and amino acid sequences. In regard to W3174, most of the aa substitutions were found in the P1, HC-Pro, and CP protein regions. The dipeptide polyprotein cleavage sites and their recognition sites (5) were located in the UKR 44189 sequence. The only difference

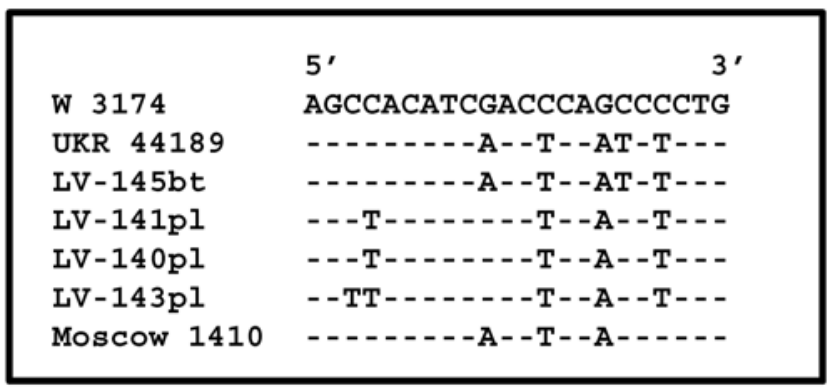

Fig. 3. Nucleic acid sequence comparison of the Plum pox virus (PPV)-W isolates in the 3174SP-F3 primer region (8675-8696 nt of the AY912055). Identical nucleotides are represented by dashes.

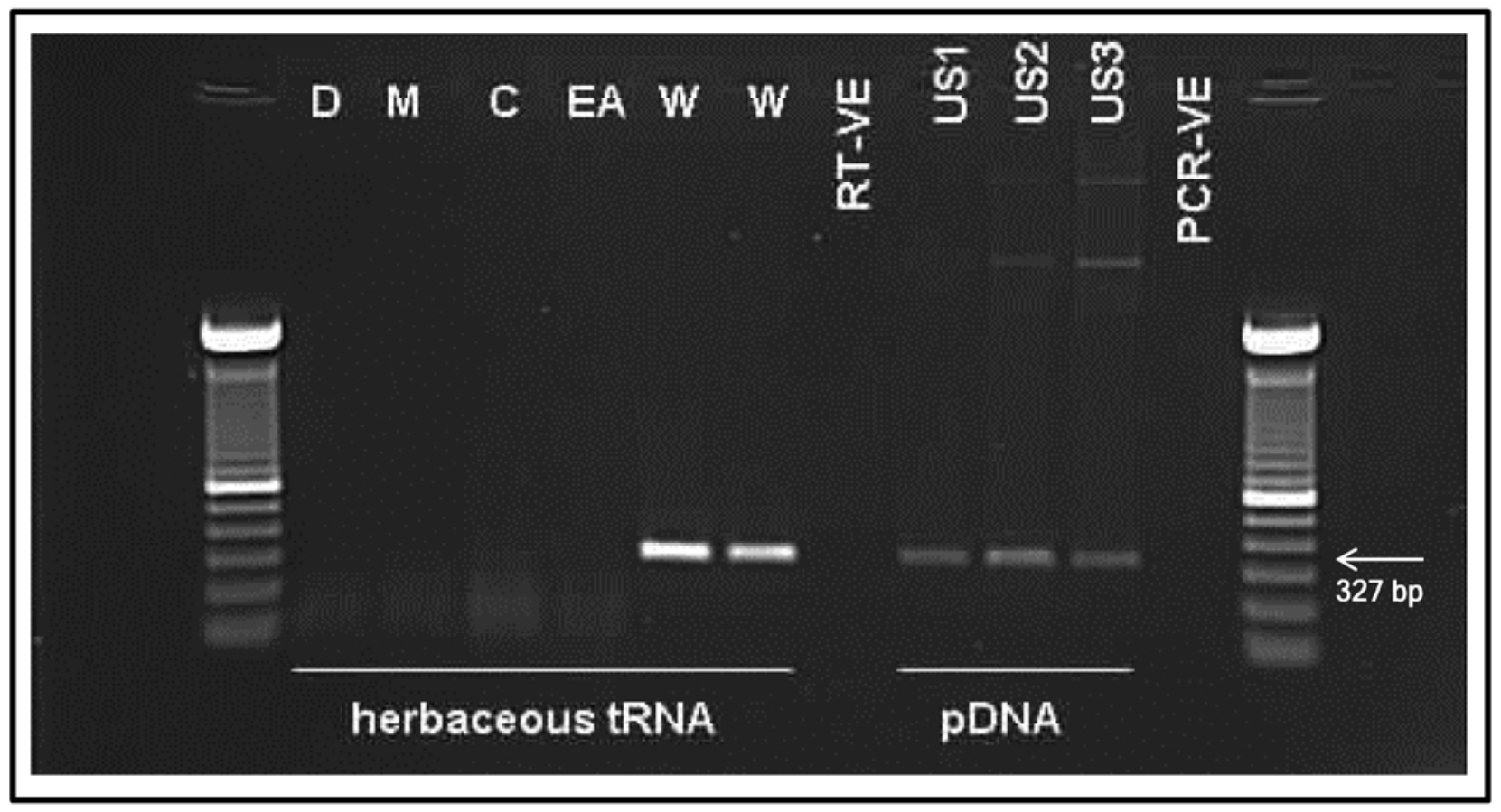

Fig. 2. Reverse transcription-polymerase chain reaction (RT-PCR) using 3174SP-F3/R1 primers. Representative Plum pox virus (PPV) isolates are indicated by strain corresponding letter. RT-VE, healthy control; PCR-VE, nontemplate control. US1, US2, and US3, three individual clones of UKR 44189 containing the coat protein gene region. pDNA, plasmid DNA; herbaceous tRNA, total RNA extracted from PPV-infected herbaceous host. 
noted with other isolates of the PPV-W group was in the autoproteolytic cleavage site at the C-terminal of the HC-Pro peptide where methionine (M) in position -4 in W3174 was substituted for arginine (K) in the UKR 44189 and the LV-145bt sequences, and threonine $(\mathrm{T})$ in the LV-141pl sequence (HQ670746). The conserved motifs KITC (39) and PTK (28), associated with aphid transmission, were found at the same positions within the HC-Pro as in the W3174 isolate. In contrast, the other insect transmission related motif, DAG (20), was located in positions 11-13 of the CP of UKR 44189 and LV-145bp in comparison to positions 12-14 in W3174, LV-140pl (HQ670745), LV-141pl, and LV-143pl (HQ670747). This is due to a single aa deletion event at position 2820 carrying valine $(\mathrm{V})$ in the three Latvian isolates, and isoleucine (I) in W3174. Comparisons of the noncoding regions of UKR 44189 and LV-145bt revealed identity levels of 99.3 and $99.5 \%$ for the $5^{\prime}$-non-coding region and the $3^{\prime}$-non-coding region, respectively. In each case, only a single nucleotide substitution was observed.

The 3'-terminal (1.4-kb fragment) of isolates UKR 44191 and UKR 44188 were also sequenced. This region encompasses the $3^{\prime}$ end of the NIb gene, entire $\mathrm{CP}$ coding region, and the $3^{\prime}$-non-coding region. The $\mathrm{CP}$ region of isolate UKR 44191 was found to be almost identical to UKR 44189 and LV-145bt at approximately $99 \%$ for the na and $98 \%$ for the aa sequences. The CP-1 N-terminus regions (6) of isolates UKR 44191, UKR 44189, and LV-145bt are $100 \%$ identical for both the $\mathrm{nt}$ and aa sequences. Of the strain
$\mathrm{W}$ isolates, the lowest identities were observed with W3174, at 93\% (aa sequence).

The CP region of isolate UKR 44188 (JN637991) is approximately 97 to $98 \%$ and 97 to $99 \%$ identical to the nt and aa sequences, respectively, of isolates of PPV strain D. The highest identities are with the D isolates LI/H (CAA56972.1) and AIN (AF332871.1). Correspondingly, a low na identity of 79 to $80 \%$ was observed when the CP of UKR 44188 was compared to isolates of strain W including UKR 44191 and UKR 44189.

Phylogenetic and recombination analyses. Phylogenetic analyses were carried out using the complete nucleotide sequence, the deduced amino acid sequence of the virus polyprotein, and the nt and aa of the CP. In each case, isolate UKR 44189 grouped with isolates of strain $\mathrm{W}$, and was most closely related to the Latvian isolate LV-145bt. Figure 5 shows phylogenetic analysis based on the complete nucleotide sequence, with the close relationship of UKR 44189 to LV-145bt supported by bootstrap values of 1,000 (100\%). Isolate UKR 44189 is more closely related to LV-145bt than LV-141pl in analyses based on the complete genome (Fig. 5), and a similar relationship is observed with the $\mathrm{CP}$ aa sequences (Fig. 6). Analysis using the $\mathrm{CP}$ aa sequences also shows the close relationship of UKR 44191 to UKR 44189 and LV-145bt supported by high bootstrap values. Phylogenetic analysis of the $\mathrm{CP}$ region of UKR 44188 isolates confirms that it is a member of the PPV-D strain with a very close relationship to the European PPV-D isolate AIN (Fig. 6). It is interesting that in phylogenetic analyses based

Table 1. Strain-specific triple antibody sandwich-enzyme-linked immunosorbent assay (TAS ELISA) for UKR 44189 strain differentiation ${ }^{\text {a }}$

\begin{tabular}{|c|c|c|c|c|c|c|c|}
\hline \multirow[b]{2}{*}{ Samples } & \multicolumn{7}{|c|}{ Detecting MAbs $^{\mathbf{b}}$} \\
\hline & 4DG5 & $\mathbf{A L}$ & AC & EA & 6B6 & $4 \mathrm{C11}$ & 4A11 \\
\hline PPV 44189 Nicotiana benthamiana & 0.084 & 0.079 & 0.096 & 0.128 & 2.381 & 2.508 & 0.870 \\
\hline PPV 44189 Prunus & 0.085 & 0.082 & 0.088 & 0.111 & 0.425 & 0.304 & $\mathrm{n} / \mathrm{t}$ \\
\hline Healthy plant & 0.090 & 0.085 & 0.138 & 0.135 & 0.082 & 0.082 & 0.083 \\
\hline Strain specific POS control ${ }^{c}$ & 0.399 & 0.523 & 1.768 & 0.739 & 0.287 & 0.250 & $0.940^{\mathrm{d}}$ \\
\hline Grinding buffer (blank) & 0.083 & 0.080 & 0.081 & 0.089 & 0.080 & 0.080 & 0.089 \\
\hline
\end{tabular}

a Average optical density (O.D.) of duplicate wells is shown.

${ }^{\mathrm{b}}$ MAbs: 4DG5 = PPV-D specific; AL = PPV-M/Rec specific; AC = PPV-C specific; EA = PPV-El Amar specific; 6B6, 4C11, and 4A11 = PPV W3174 derived.

${ }^{\mathrm{c}}$ Positive controls: PPV-D = isolate UKR 44188; PPV-M = plum isolate from Bulgaria; PPV-C = lyophilized ELISA control (Agritest); PPV-El Amar = isolate from Egypt maintained on GF305: PPV-W = isolate 3174.

${ }^{\mathrm{d}}$ PPV-D was used as a positive control for 4A11 MAb that recognizes a universal PPV epitope.

W3174

UKR 44189

LV-145bt

LV-141pl

LV-143pl

Moscow 1410

W3174

UKR 44189

LV-145bt

LV-141pl

LV-143pl

Moscow 1410

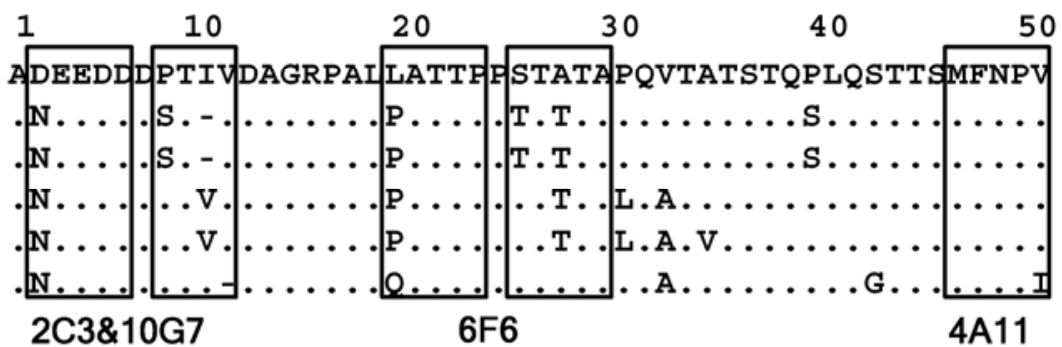

$\begin{array}{llllll}51 & 60 & 70 & 80 & 90 & 100\end{array}$

FTPATTQPSVKPTTSATINPTSFGVVGNESVAPSSSNALTNLERDRDVDA

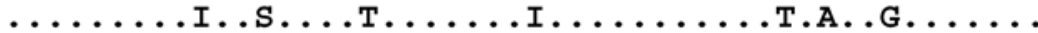

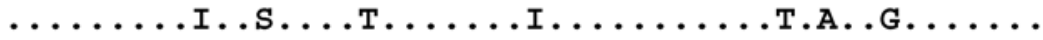

...............................

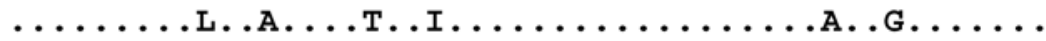

$\ldots \ldots \ldots \ldots \ldots \ldots$ T. . . . . . . . .

Fig. 4. Multiple sequence alignment of the first 100 amino acids of the coat protein hyper-variable region of selected Plum pox virus (PPV)-W isolates. W3174-derived MAbs epitope recognition sites according to Croft et al. (7) are boxed with IDs below the boxes. Identical amino acids are represented by dots and deletions by dashes. 
on the complete genomes (nt) or the $\mathrm{CP}$ aa sequences, isolates BY101 and BY181 group very closely to known PPV-C isolates (Figs. 5 and 6, respectively).

SimPlot analysis reveals some evidence of recombination events between known isolates of PPV-W. Figure 7 shows that bootscanning of four isolates of PPV-W strain (with complete genomes available) reveals recombination signals in the $\mathrm{P} 3$ coding region (around nt position 3000), and in the NIb coding region (approximately $7600-7810 \mathrm{nt}$ ). Isolate UKR 44189 is very closely related to LV-145bt except in these two regions of the genome. Specifically, UKR 44189 is more closely related to W3174 than to LV-145bt in the NIb recombination region. Attempts to confirm these signals using the program RDP3 were unsuccessful.

\section{Discussion}

PPV isolates were intercepted in Prunus germplasm hand carried into the United States from the Ukraine in 2004. Strain typing and partial sequencing revealed that UKR 44189 and UKR 44191 were closely related to PPV-W3174 (25), the only isolate described at that time of the newly proposed PPV-W strain (13). Although PPV was found in the Ukraine a long time ago (30), PPV-D has been the only strain reported so far from this country $(16,27)$.

\subsection{2}

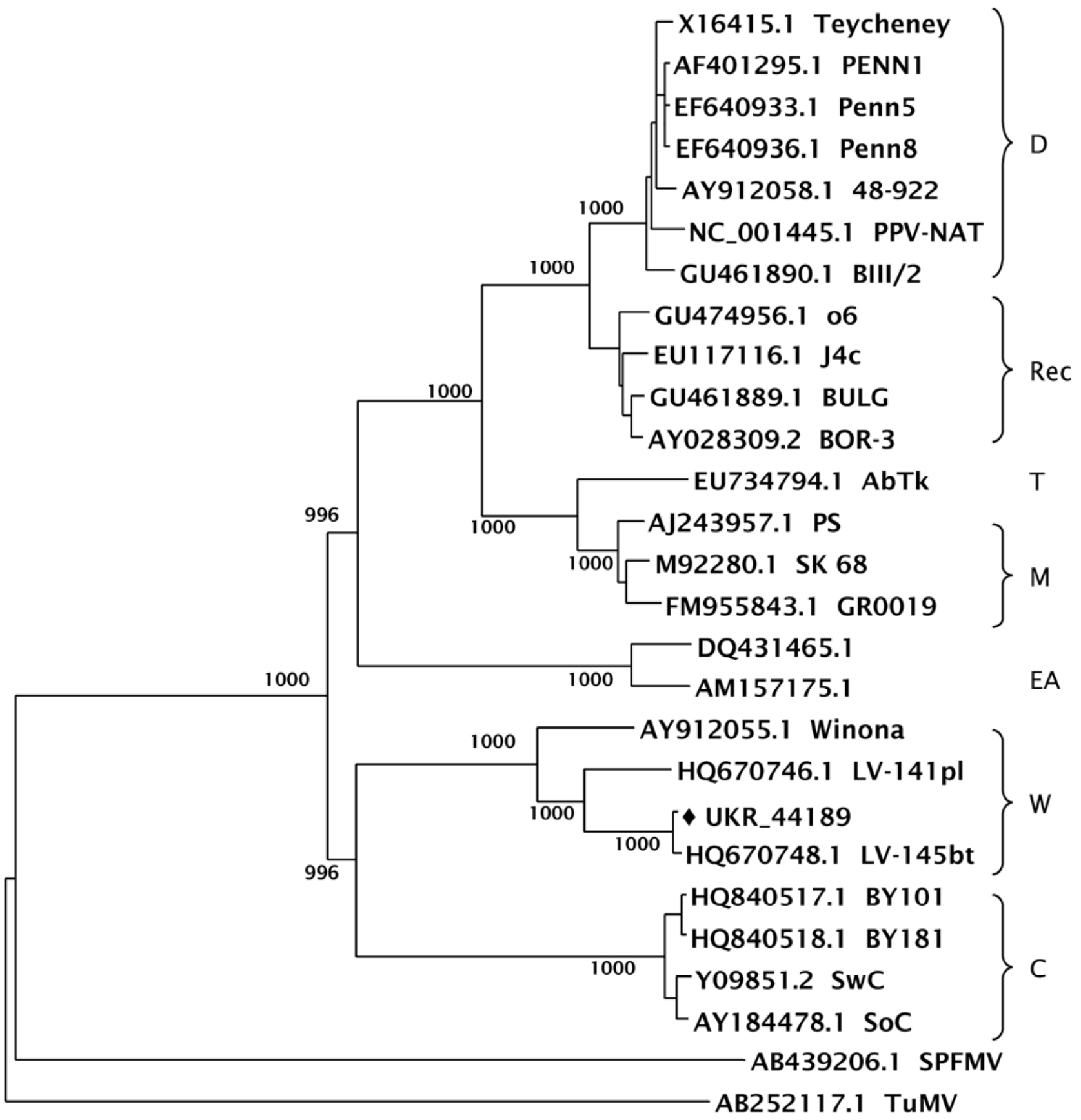

Fig. 5. Phylogenetic analysis based on the complete genome sequences (nucleotides) of selected isolates of all seven recognized strains of Plum pox virus. The accession numbers and identity of the isolates are given. The tree was constructed using the N-J Tree option of Clustal-X (29). Bootstrap values out of 1,000 replicates are shown, and the scale bar indicates the number of substitutions per residue. Potyviruses Sweet potato feathery mottle virus and Turnip mosaic virus were used to form an out group. Strain affiliation indicated on the right; isolate UKR 44189 is identified by a diamond. 
Therefore, our finding validated the existence of the PPV-W strain contributing to the current knowledge of PPV strain variability and distribution.

The newly described PPV-W isolates from Ukraine were tested with already existing PPV-W3174 specific molecular (12) and serological diagnostic tools (7). The results obtained were unexpected. When relevant sequences of UKR 44189 and W3174 were compared, it became clear that there were significant differences on both the nucleic acid and protein levels that undoubtedly contributed to the inconsistent results. A five-nucleotide mismatch located in the $3^{\prime}$-half of the PPV-W 3174SP-F3 primer site was found that may have contributed to the inefficient amplification of UKR 44189 with W3174 specific primers (Fig. 3). These substitutions were also found later in all four PPV-W isolates from Latvia (9), suggesting that they also might not amplify efficiently with this primer pair. On the other hand, Sheveleva et al. (34) reported that the 3174SP-F3/R1 primer pair amplified the expected 327-bp product from the PPV-W 1410 isolate from Moscow (HQ326086). When the sequence of this isolate was examined, no mismatches were found in the $3^{\prime}$ end of the F3 primer sequence of PPV-W 1410 , confirming the critical role of the $3^{\prime}$ end 5 nucleotides for primer recognition and amplification. New PPV-W specific primers have been developed (9) based on the W3174 and Latvian isolates sequences. These are expected to identify UKR 44189, since the primer sequences were found to be conserved in the UKR 44189 genome.

On the protein level, reaction of UKR 44189 with W3174-derived 10G7 and 2C3 MAbs was prevented by the aa changes noted in the epitope sites. Analysis of the first 100 amino acids of the $\mathrm{CP}$ of PPV-W isolates revealed a significant level of variability (Fig.

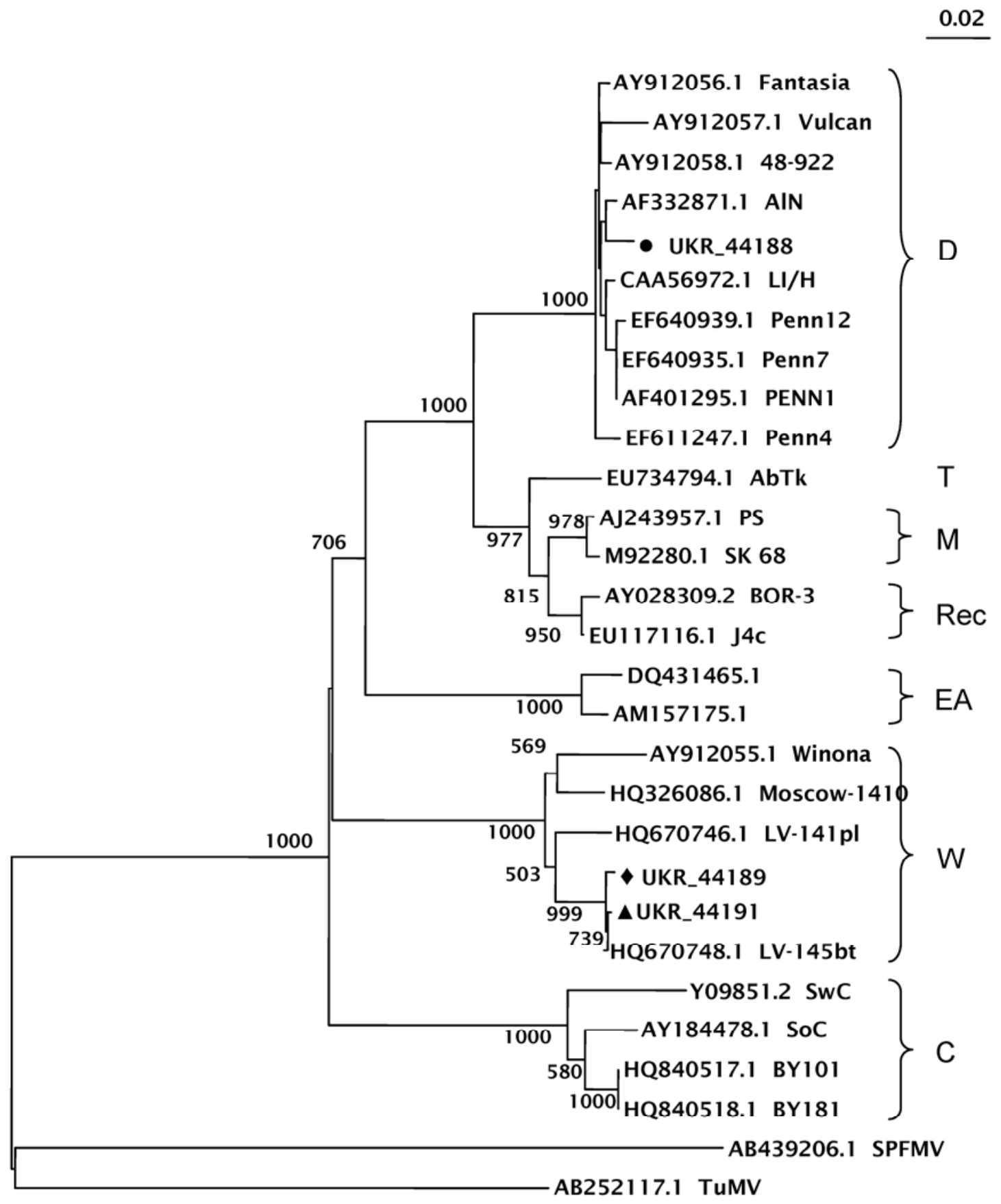

Fig. 6. Phylogenetic analysis based on the deduced amino acid sequences of the coat protein of selected isolates of all seven recognized strains of Plum pox virus. The accession numbers and identity of the isolates are given. The tree was constructed using the $\mathrm{N}-\mathrm{J}$ Tree option of Clustal-X (29+). Bootstrap values out of 1,000 replicates are shown, and the scale bar indicates the number of substitutions per residue. The potyviruses Sweet potato feathery mottle virus and Turnip mosaic virus were used to form an outgroup. Strain affiliation indicated on the right; isolate UKR 44189 identified by a diamond; UKR 44191 by a triangle; and UKR 44188 by a circle. 
4). While UKR 44189 and LV-145bt sequences were identical in this region, there were 13 aa substitutions plus one aa deletion event (position 10) in comparison to the W3174 isolate. The other three PPV-W isolates for which a sequence is available in GenBank, LV-141pl, LV-143pl, and Moscow 1410, also differ by 10 to 13 amino acids from W3174. Some of the substitutions found in this region appear to affect MAbs recognition (7). All five isolates have aa substitutions in positions 2 and 8 in comparison to W3174. In addition, UKR 44189 and LV-145bp lack isoleucine (I) in position 10. In PPV-W isolate 1410 from Moscow, isoleucine is present but valine (V) in position 11 is missing. LV-141pl and LV-143pl have no deletion in position 10 of the $\mathrm{CP}$, but isoleucine (I) in W3174 is substituted with valine (V). These changes likely contributed to the failed reactions of all three Latvian isolates (9) and UKR 44189 with 2C3/10G7 MAbs. This may also affect recognition of Moscow 1410 isolate. There are three substitutions in the 6F6 MAbs sites (positions 19-23 and 25-29) in the UKR 44189 and LV-145bt, two substitutions each in LV-141pl and LV-143pl, and one in Moscow 1410 isolate in comparison to W3174 (Fig. 4). These results suggest that development of diagnostic tools should always be based on more than one isolate (if available) to account for the sequence variability within the group/strain and to ensure robustness and reliability of the assays.

Phylogenetic analyses confirmed the strain identity of PPV isolates UKR 44188 (D strain), UKR 44189 (W strain), and UKR 44191 (W strain). Isolates UKR 44189 and UKR 44191 are very closely related to LV-145bt from Latvia (Figs. 5 and 6). The genetic fingerprint, including $100 \%$ identity of the CP1 region, suggests a common source/origin for all three isolates. In addition, UKR 44189 and LV-145bt isolates were both found in wild plum/blackthorn ( $P$. spinosa) trees.

SimPlot analysis (Fig. 7) revealed two possible recombination signals involving UKR 44189 and other PPV-W isolates. Although UKR 44189 was most closely related to LV-145bt across the entire genome, in the 7600-7810 nt region, UKR 44189 was more closely related to isolate $\mathrm{W} 3174$. Even though recombination events have been described between strains of PPV $(6,10,11,33)$, this is the first identification of a potential recombination event between isolates. Salminen (32) indicated that there must be a certain amount of genetic variation between lines to allow for identification of the recombination events. Isolates of PPV-W strain appear to display the greatest genetic diversity (93 to 99\% identity) among PPV strains, compared to a range of 95 to $100 \%$ seen for isolates of other strains $(9,24)$. One can assume that there are recombination events occurring among PPV isolates that co-infect a single plant, but the genetic diversity of PPV-W isolates (9) seems to make it possible to obtain the necessary evidence. As more sequence data become available for PPV-W isolates, this should allow confirmation of this phenomenon.

Failure to detect the UKR 44189 and UKR 44191 isolates in GF 305 and $P$. tomentosa, after several years of testing, seems to indicate that these are not hosts for these two isolates of PPV-W. However, isolates were consistently detected in the original $P$. spinosa material grafted onto the experimental hosts. This provides interesting host range information associated with these PPV-W isolates.

Additional epidemiological information available suggests a common origin of the currently known PPV-W isolates. When PPV W3174 was first described in Canada, the property owner where the tree was located indicated a possible Eastern European origin for the tree, although it was not proven (15). Surprisingly, two PPV-W isolates (UKR 44189 and UKR 44191) have been confirmed in Prunus germplasm with a known origin from that region (25). The documented source of this germplasm was the Prunus cultivar collection of the Ukrainian Horticultural Institute in Donetsk. Recently, additional PPV-W isolates were reported in a varietal tree collection in Latvia (9) and in a botanical garden in Moscow, Russia (34). This underscores the possibility that PPV-W isolates might have originated from a common source and spread through the Prunus breeding system of the former Soviet Republics. These findings emphasize the importance of monitoring disease status of varietal/botanical collections and of using only virusclean material for propagation of similar collections. PPV-W is a newly emerging strain of the virus, and because of its limited distribution, little is known regarding its biology and epidemiology, and its possible impact on the Prunus fruit industry. The importation of exotic PPV-W isolates into the United States was avoided in this case, but this event demonstrates the ongoing need for vigi-

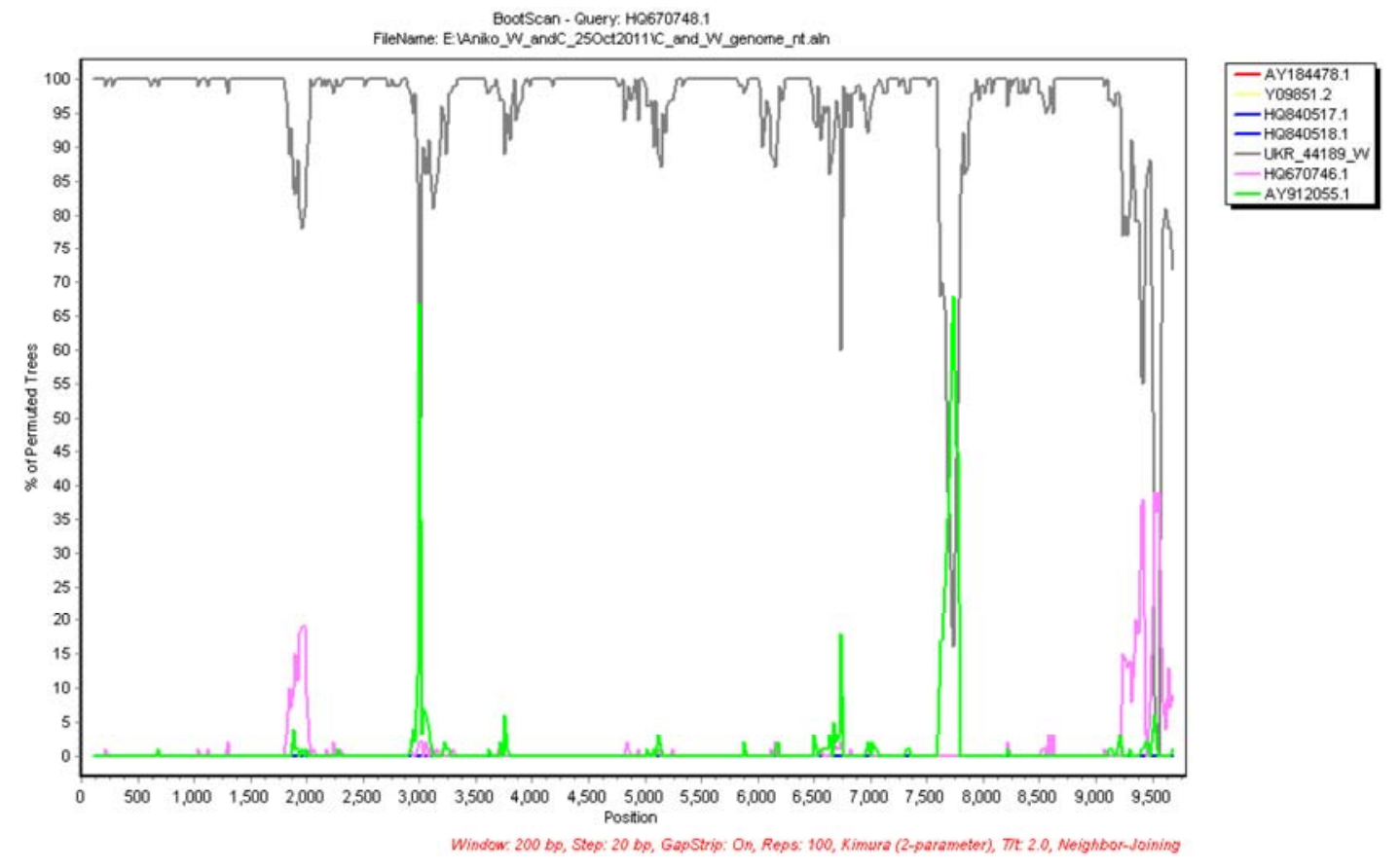

Fig. 7. Simplot bootscanning analysis (17) comparing Plum pox virus (PPV)-W isolates with complete genome sequences available, also isolates or putative isolates of closely related PPV strain C. The putative W ancestral type isolate LV-145bt (HQ670748) was used as the query isolate. The UKR 44189 isolate is indicated in gray. Virus isolates include: strain W; UKR 44189 (JN596110), W3174 (AY912055), LV-141pl (HQ670746), LV-145bt (HQ670748), and strain C or C type; SoC (AY184478), SwC (Y09851), BY101 (HQ840517), and BY181 (HQ840518). 
lance in preventing the unauthorized introduction of Prunus plant material into the United States, especially in light of the enormous amount of resources utilized to successfully eradicate PPV from Pennsylvania and Michigan and the on-going efforts to achieve eradiation in the state of New York.

\section{Acknowledgments}

We thank Dr. Mariano Cambra (IVIA, Valencia, Spain) for kindly providing the $\mathrm{Al}$ and 4DG5 MAbs.

\section{Literature Cited}

1. Acuña, R. 1993. Outbreaks of Plum pox virus in Chile. (Abstr.) Eur. Mediterr. Plant Protection Organization Conference on Plum pox virus. Bordeaux, France.

2. Atanasoff, D. 1932/1933. Plum pox. A new virus disease. Yearbook. Fac. Agric. Univ. Sofia 11:49-69.

3. Candresse, T., and Cambra, M. 2006. Causal agent of Sharka disease: Historical perspective and current status of plum pox virus strains. Bull. OEPP/EPPO Bull. 36:239-246.

4. Candresse, T., Cambra, M., Dallot, S., Lanneau, M., Asensio, M., Gorris, M. T., Revers, F., Macquaire, G., Olmos, A., Boscia, D., Quiot, J. B., and Dunez, J. 1998. Comparison of monoclonal antibodies and polymerase chain reaction assays for the typing of isolates belonging to the $\mathrm{D}$ and $\mathrm{M}$ serotypes of Plum pox potyvirus. Phytopathology 88:198-204.

5. Carrington, J. C., and Herdon, K. L. 1992. Characterization of the potyviral HC-Pro authoproteolytic cleavage site. Virology 187:308-315.

6. Cervera, M. T., Riechmann, J. L., Martin, M. T., and Garcia, J. A. 1993. 3'Terminal sequence of the Plum pox virus PS and 46 isolates: Evidence for RNA recombination within the potyvirus group. J. Gen. Virol. 74:329-334.

7. Croft, H., Malinowski, T., Krizbai, L., Mikec, I., Kajic, V., Reed, C., Varga, A., and James, D. 2008. Use of Luminex xMAP-derived Bio-Plex beadbased suspension array for specific detection of PPV W and characterization of epitopes of the coat protein gene of the virus. J. Virol. Methods 153:203-231

8. Dal Zotto, A., Ortego, J. M., Raigón, J. M., Caloggero, S., Rossini, M., and Ducasse, D. A. 2006. First report in Argentina of Plum pox virus causing Sharka disease in Prunus. Plant Dis. 90:523.

9. Glasa, M., Malinowski, T., Predajňa, L., Pupola, N., Dekena, D., Michalczuk, L., and Candresse, T. 2011. Sequence variability, recombination analysis, and specific detection of the $\mathrm{W}$ strain of Plum pox virus. Phytopathology 101:980-985.

10. Glasa, M., Marie-Jeanne, V., Labonne, G., Subr, Z., Kudela, O., and Quiot, J. B. 2004. A natural population of recombinant Plum pox virus is stable and competitive under field condition. Eur. J. Plant Pathol. 108:843-853.

11. Glasa, M., Palkovics, L., Kominek, P., Labonne, G., Pittnerova, S., Kudela, O., Candresse, T., and Subr, Z. 2004. Geographically and temporally distant natural recombination isolates of Plum pox virus (PPV) are genetically very similar and form a unique PPV subgroup. J. Gen. Virol. 85:2671-2681.

12. James, D., and Varga, A. 2004. Preliminary molecular characterization of Plum pox potyvirus isolate W3174: Evidence of a new strain. Acta Hortic. 657:177-182.

13. James, D., and Varga, A. 2005. Nucleotide sequence analysis of Plum pox virus isolate W3174: Evidence of a new strain. Virus Res. 110:143-150.

14. James, D., and Varga, A. 2011. Genetic diversity of Canadian isolates of Plum pox virus and its significance. Acta Hortic. 899:29-38.

15. James, D., Varga, A., Thompson, D., and Hayes, S. 2003. Detection of a new and unusual isolate of Plum pox virus in plum (Prunus domestica). Plant Dis. 87:1119-1124.

16. Kondratenko, P., and Udovychenko, V. 2006. Plum pox virus (PPV) in Ukraine. Bull. OEPP/EPPO Bull. 36:217.

17. Levy, L., Damsteegt, V., and Welliver, R. 2000. First report of Plum pox virus (Sharka disease) in Prunus persica in the United States. Plant Dis. $84: 202$.

18. Levy, L., Lee, I.-M., and Hadidi, A. 1994. Simple and rapid preparation of infected plant tissue extracts for PCR amplification of virus, viroid, and ML0 nucleic acids. J. Virol. Methods 49:295-304.

19. Lole, K. S., Bollinger, R. C., Paranjape, R. S., Gadkari, D., Kulkarni, S. S., Novak, N. G., Ingersoll, R., Sheppard, H. W., and Ray, S. C. 1999. Fulllength human immunodeficiency virus type 1 genomes from subtype $\mathrm{C}$-infected seroconverters in India, with evidence of intersubtype recombination. J. Virol. 73:152-160.

20. López-Moya, J. J., Canto, T., Díaz-Ruíz, J. R., and López-Abella, D. 1995. Transmission by aphids of a natural non-transmissible Plum pox virus isolate with the aid of Potato virus Y helper component. J. Gen. Virol. 76:2293-2297.

21. MacKenzie, D. J., McLean, M. A., Mukerji, S., and Green, M. 1997.
Improved RNA extraction from woody plants for the detection of viral pathogens by reverse transcription-polymerase chain reaction. Plant Dis. $81: 222-226$.

22. Maejima, K., Hoshi, H., Hashimoto, M., Himeno, M., Kawanishi, T, Komatsu, K., Yamaji, Y., Hamamoto, H., and Namba, S. 2010. First report of Plum pox virus infecting Japanese apricot (Prunus mume Sieb. et Zucc.) in Japan. J. Gen. Plant Pathol. 76:229-231.

23. Martin, D. P., Lemey, P., Lott, M., Moulton, V., Posada, D., and Lefeuvre, P. 2010. RDP3: A flexible and fast computer program for analyzing recombination. Bioinformatics 26:2462-2463.

24. Matic, A., Elmaghraby, I., Law, V., Varga, A., Reed, C., Myrta, M., and James, D. 2011. Serological and molecular characterization of isolates of Plum pox virus strain El Amar to better understand its diversity, evolution, and unique geographic distribution. J. Plant Pathol. 93:303-310.

25. Mavrodieva, V., Mock, R., and Levy, L. 2006. Molecular characterization of PPV isolates from plum germplasm illegally imported from Ukraine. Abstract Book p. 112; XXth Int. Sympos. Virus Virus-like Dis. Temperate Fruit Crops and XIth Int. Sympos. Small Fruit Virus Dis., Antalya, Turkey, 2006.

26. Nemchinov, L., Hadidi, A., Maiss, E., Cambra, M., Candresse, T., and Damsteegt, V. 1996. Sour cherry strain of Plum pox potyvirus (PPV): Molecular and serological evidence for a new subgroup of PPV strains Phytopathology 86:1215-1221.

27. Norkus, T., Staniulis, J., Žižyte, M., Melnyk, M., Yusko, L., Snihur, H, Budzanivska, I., and Polischuk, V. 2008. Molecular identification of plum pox virus isolates from Lithuania and Ukraine. Zemdirbyste-Agric. 95:277285.

28. Peng, Y., Kadoury, D., Gall-On, A., Huet, H., Wang, Y., and Racch, B. 1998. Mutation in the HC-Pro gene of zucchini yellow mosaic virus: Effects on aphid transmission and binding to purified virions. J. Gen. Virol. 79:897904.

29. Perriere, G., and Gouy, M. 1996. WWW-Query: An online retrieval system for biological sequence banks. Biochimie 78:364-369.

30. Piskun, N. I. 1969. Plum pox virus in Ukraine. Plant Prot. 6:54

31. Saitou, N., and Nei, M. 1987. The neighbor-joining method: A new method for reconstructing phylogenetic trees. Mol. Biol. Evol. 4:406-425.

32. Salminen, M. 2003. Detecting recombination in viral sequences. Pages 348377 in: The Phylogenetic Handbook: A Practical Approach to DNA and Protein Phylogeny. M. Salemi and A.-M. Vandamme, eds. University Press, Cambridge, UK.

33. Serce, C. U., Candresse, T., Svanella-Dumas, L., Krizbai, L., Gazela, M. and Caglayan, K. 2009. Further characterization of a new recombinan group of Plum pox virus isolates, PPV-T, found in orchards in the Ankara province of Turkey. Virus Res. 142:121-126.

34. Sheveleva, A., Chirkov, S., and Nemova, E. 2011. Detection of a new Winona-like Plum pox virus isolate in naturally infected Canadian plum (Prunus nigra) in Russia. Acta Hortic. 899:49-56.

35. Snover-Clift, K. L., Clement, P. A., Mungari, R. J., Jablonski, R., Mavrodieva, V. A., Negi, S., and Levy, L. 2007. First Report of the Plum pox virus in New York State. Plant Dis. 91:1512.

36. Spiegel, S., Kovalenko, E. M., Varga, A., and James, D. 2004. Detection and partial molecular characterization of two Plum pox virus isolates from plum and wild apricot in Southeast Kazakhstan. Plant Dis. 88:973-979.

37. Thompson, D., McCann, M., MacLeod, M., Lye, D., Green, M., and James, D. 2001. First report of Plum pox virus in Ontario, Canada. Plant Dis. $85: 97$.

38. Thompson, D., Varga, A., De Costa, H., Birch, C., Glasa, M., and James, D. 2009. First report of Plum pox virus recombinant strain on Prunus spp. in Canada. Plant Dis. 93:674.

39. Urcuqui-Inchima, S., Haenni, A.-L., and Bernardi, F. 2001. Potyvirus proteins: A wealth of functions. Virus Res. 74:15-175.

40. USDA APHIS 2006. USDA Laboratory confirms plum pox virus in Michigan. News release. http://aphis.usda.gov/newsroom/content/2006/08/ ppvmich.shtml

41. Wetzel, T., Candresse, T., Macquaire, G., Ravelonandro, M., and Dunez, J. 1992. A highly sensitive immunocapture polymerase chain reaction method for plum pox potyvirus detection. J. Virol. Methods 39:27-37.

42. Wetzel, T., Candresse, T., Ravelonandro, M., Delbos, R. P., Mazyad, H. Aboul-Ata, A. E., and Dunez, J. 1991. Nucleotide sequence of the 3 terminal region of the RNA of the El Amar strain of Plum pox potyvirus. J. Gen. Virol. 72:1741-1746.

43. Wetzel, T., Candresse, T., Ravelonandro, M., and Dunez, J. 1991. A polymerase chain reaction assay adapted to Plum pox potyvirus detection. J. Virol. Methods 33:355-356.

44. Wilkins, M. R., Gasteiger, E., Bairoch, A., Sanchez, J.-C., Williams, K. L., Appel, R. D., and Hochstrasser, D. F. 1998. Protein identification and analysis tools in the ExPASy Server. In: 2-D Proteome Analysis Protocols. A. J. Link, ed. Humana Press, New Jersey. 